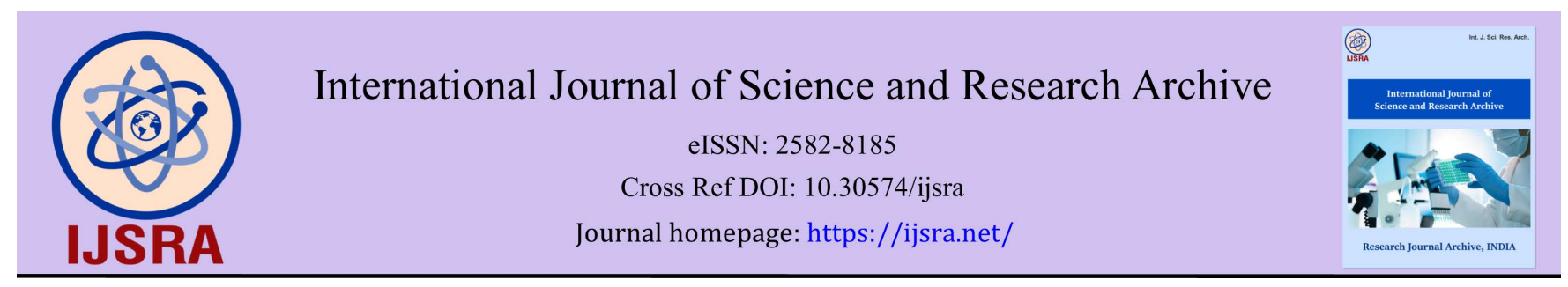

(RESEARCH ARTicle)

\title{
Environmental impact of the Kinshasa technical waste landfill center on the flora of Mpasa
}

\author{
Jean DJONGA LOHAKA 1, IDRISSA ASSUMANI ZABO 2, * Rombaut TAMASALA NDOMBE 1, Don béni LUKAU \\ NSIMBA ${ }^{3}$, Albert NGOMA MALANDA KIMINU ${ }^{4}$ and Jean ZA NZA NTEZOLO ${ }^{5}$ \\ ${ }^{1}$ Department of Biology, Faculty of Sciences, National Pedagogical University in Kinshasa, DR Congo. \\ 2 Department of Biology, Faculty of Sciences and Principal animator of Research Unit 73 at the Interdisciplinary Research \\ Center of the National Pedagogical University, DR Congo. \\ 3 Teacher at KIMWENZA High School, Kinshasa DR Congo. \\ ${ }^{4}$ Researcher at the Research Center in Applied and Technological Sciences, DR Congo. \\ ${ }^{5}$ Researcher at the Interdisciplinary Research Center of the National Pedagogical University, DR Congo.
}

International Journal of Science and Research Archive, 2022, 05(01), 092-102

Publication history: Received on 01 January 2022; revised on 14 February 2022; accepted on 16 February 2022

Article DOI: https://doi.org/10.30574/ijsra.2022.5.1.0040

\begin{abstract}
The Kinshasa Technical Waste Landfill Center (TWLC) is a 250-hectare space erected to receive and bury waste from nine municipalities in the city of Kinshasa during the period from 2010 to 2017. Four years after the work stoppage, it is currently colonized by vegetation.

This research consists in evaluating the impact of waste burial activities on the flora of MPASA. The sampling sites selected are the surrounding environment serving as a control, the lockers in which the waste was buried and the lagoon basins which received the leachate resulting from the decomposition of the waste in the lockers. The floristic and soil samples were respectively taken for identification and laboratory analysis.

The results reveal a discrepancy between the sites. Floristically, the lockers are colonized by 33 plant species; the surrounding environment has 28 species and the lagooning basins, pauci specific, record only 4 species. On the pedological level, the $\mathrm{pH}$ is acidic in the surrounding environment while it is alkaline in the lockers and lagoon basins.
\end{abstract}

Keywords: Technical Waste Landfill Center; Waste burial activities; Environmental impact; Flora; pH soil

\section{Introduction}

Human activity has always generated waste. Each era has had its mode of treatment and its specific problems. Landfilling was the solution that initially seemed to be the most practical, moving over time from wild dumps to controlled dumps; the latter receiving bulk waste of all types and thus ending up being a threat to the environment themselves [1].

Considering waste management as a problem of public hygiene, the authorities mainly focus on the cleanliness of public spaces and the disposal of waste outside cities. But the strong waves of population growth from the 1960s and the development of non-regulatory housing districts, particularly in Africa, made the problem of waste an international environmental problem issue at the same time an opportunity for the private sector. Indeed, from the beginning of the

\footnotetext{
${ }^{*}$ Corresponding author: IDRISSA ASSUMANI ZABO

Department of Biology, Faculty of Sciences and Principal animator of Research Unit 73 at the Interdisciplinary Research Center of the National Pedagogical University, DR Congo.
}

Copyright (C) 2022 Author(s) retain the copyright of this article. This article is published under the terms of the Creative Commons Attribution Liscense 4.0. 
1990s, this sector was the subject of the same recommendations from international donors, notably via the World Bank and the United Nations Development Program [2-4].

These programs recommended a technicalization of the operation and an institutionalization of the management by recourse to the formal or informal private sector. These difficulties have led to changes in the management model recommended by donors, particularly in Africa, where they encourage the use of pre-collectors in outlying districts [5].

The demographic explosion in most African cities leads to a quantitative growth in the production of both household and industrial waste. Waste management remains a problem in African cities. States, local elected officials, technicians and users are looking for ways to ensure the cleanliness of cities and preserve their environment [6].

In Algeria, for example, the considerable evolution of household waste and its impact on the environment have developed, since the 90s, a growing sensitivity of the population to environmental issues. The amount of municipal solid waste produced is constantly increasing. It is estimated at around 11 million tons. An Algerian produces an average of $0.8 \mathrm{~kg}$ of waste daily [7].

A qualitative reinforcement of the regulatory framework in terms of waste management was born in December 2001 with the promulgation of law 01-19 which imposes constraints in the choice of location of waste landfill sites and their methods of disposal exploitation. This law established the national program for the integrated management of urban solid waste and the communal plan for the management of household waste, with the aim of eradicating illegal dumping. This program has enabled the Wilaya of Algiers to acquire several large-capacity technical waste landfills [7].

Many laws on waste management refer to the principle of proximity. The aim is to limit the distance between waste producers (households, businesses) and disposal or even treatment facilities. However, this principle generally remains rather vague in its terms of application, even contradictory with other criteria for choosing the destination of waste, in particular economic: the cheapest treatment is not necessarily the closest [8].

The efficiency of a Technical Waste Landfill Center (TWLC) is based on the characteristics of the soil and subsoil, making it possible to define the devices necessary for the protection of the environment. The growing demography in the City of Kinshasa requires more spaces to accommodate the solid waste produced by the population. Otherwise, the inhabitants throw the waste in the street or in the drainage gutters making the city unsanitary. To deal with this situation, the Kinshasa Technical Waste Landfill Center (TWLC) was erected at MPASA in 2010. It covers 250 hectares of which only 30 have been exploited $[9,10]$.

The problem of waste management in Kinshasa and the establishment of the TWLC in MPASA arouse scientific interest. In order to assess the impact of the TWLC on the flora and soil of MPASA four years after its decommissioning, the following questions arise:

- What is the impact of the TWLC on the flora and soil of MPASA, the environment where it is located?

- Concretely, what is the degree of similarity between the flora of the surrounding environment and those of the lagoon basin and the locker?

This study aims to assess the impact of TWLC on the flora and soil of MPASA. Specifically, it consists of:

- Inventory the plant species on the 3 previously chosen sampling sites;

- Take floristic and soil samples respectively for identification and laboratory analysis;

Compare the results obtained.

\section{Material and methods}

\subsection{Study area}

The Kinshasa Technical Waste Landfill Center is located $35 \mathrm{~km}$ from the city center. It is located in Mpasa, in the commune of N'sele, Q. Mobanse, to the East of the City-Province of Kinshasa. It is a concession of 250 hectares of which 220 remain unexploited until now (Figure 1). 


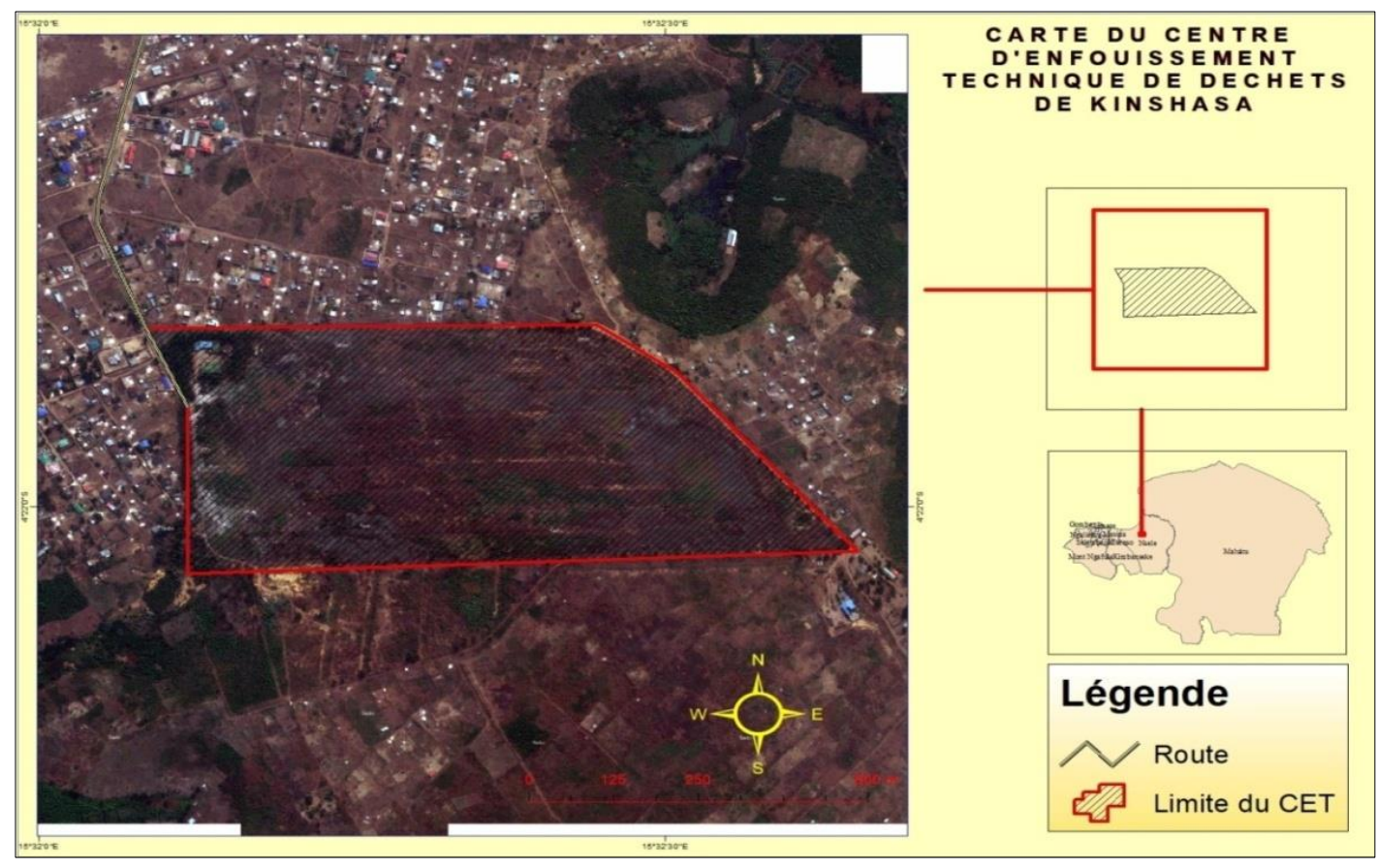

Figure 1 Geographic location of TWLC Kinshasa

\subsection{Methods}

\subsubsection{Experimental apparatus}

The experimental device includes 3 sites:

- $\mathrm{T}_{0}$ : The surrounding environment, which reflects both the edaphic and floral conditions that prevailed before the installation of the Technical Waste Landfill Center;

- $\mathrm{T}_{1}$ : The lockers which, four years ago, served as a place for storing garbage in successive layers 1 meter thick;

- $\mathrm{T}_{2}$ : The lagooning basins which collected the leachate from the various lockers channeled through a sealed gutter in order to rid it of substances harmful to nature.

\subsubsection{Field study methods}

The inventory of lockers and basins was carried out using the phytosociological method based on the transect technique. That of the surrounding environment referred to the method of floristic surveys consisting in systematically identifying the plants present around the lockers and basins. In general, the execution of the surveys was mainly inspired by previous work [11-18].

\subsubsection{Laboratory study methods}

Floristic study

The identification of the plants was carried out in the field by the taxonomist of the Laboratory of Systematic Botany and Plant Ecology of the Department of Biology of the National Pedagogical University Pr IDRISSA ASSUMANI.IDRISSA ASSUMANI ZABO. It was confirmed by comparison with the specimens kept in the Research Laboratory of the Department of Biology at the National Pedagogical University and that of INERA at the University of Kinshasa. The phylogenetic classification of the inventoried species was carried out according to APG IV19].

\section{Ecological study}

Ecological analyzes have distinguished the following types: Morphological Types (TM), Biological Types (TB), and Diaspore Types (TD). 
Phytogeographic analysis

The identification of phytogeographic groups refers to previous work $[12,20]$.

Determination of the soil pH of the TWLC and its surroundings

The Protocol used was determined by the Kinshasa plant clinic:

- Take soil samples from several places in the field

- Put these samples in the different khaki envelopes

- Close and label the envelopes

- Crush the soil samples in a mortar with pestle

- Weigh $10 \mathrm{~g}$ of crushed soil, put in a pyrex tube, add $10 \mathrm{ml}$ of distilled water finally shake with the vortex for 30 seconds, then let stand for 3 minutes

- $\quad$ Measure the $\mathrm{pH}$ with the electronic $\mathrm{pH}$ meter

- $\quad$ Read the results.

\subsubsection{Comparative floristic analysis of sites}

The comparative analysis of these different sites consisted in determining the Sorrëssen Similarity Index (SI). The SORENSSEN index weights the co-occurrence term by 2 .

$$
\text { Its formula is } I S=2 a /((2 a+b+c))
$$

Interpretation

- If IS is greater than $0.7(x>0.7)$ then the similarity is very strong between the sites or the stations;

- If IS varies between 0.5 and $0.69(0.5 \leq \mathrm{x} \leq 0.69)$ then the similarity is average, with disparities;

If IS is less than $0.5,(x<0.5)$ then the difference between the flora of the sites is very pronounced.

\section{Results}

\subsection{Characteristics of species according to biological, ecological and phytogeographical parameters}

The related results are shown in Table 1.

Legend

TM: Morphological types

- A : tree

- arb : shrub

- Han : Annual grass

- Hvi : perennial grass

- L : Liana

TB: Biological types

- Ph: Phanerophyte

- Ch: Chamephyte

- Hmi : Hemicryptophyte

- Géo : Geophyte

DP: Phytogeographic distribution

- TLD : Very wide Distribution 
- $\quad$ Eli : Liaison species

- $\quad$ EBG : Guinean base element

TD: Diaspore types

- An : Anemochorous

- Zoo : Zoochorous

- Aut : Autochorous

Site

- T0: Surrouding environment

- T1 : Locker

- T2 : Lagoon basin

Table 1 Characteristics of species according to biological, ecological and phytogeographical parameters

\begin{tabular}{|c|c|c|c|c|c|c|c|}
\hline \multirow{2}{*}{ ESPECES } & \multirow{2}{*}{ TM } & \multirow{2}{*}{ TB } & \multirow{2}{*}{ TD } & \multirow{2}{*}{ DP } & \multicolumn{3}{|c|}{ SITES } \\
\hline & & & & & $\mathbf{T}_{\mathbf{0}}$ & $\mathbf{T}_{\mathbf{1}}$ & $\mathbf{T}_{2}$ \\
\hline 1. Annona senegalensis Pers.subsp. oulotricha Le Thomas & arb & $\mathrm{MsPh}$ & Sarco & At & $\mathrm{x}$ & & \\
\hline 2. Persea americana Mill. & A & $\mathrm{MsPh}$ & Sarco & Pan & & $\mathrm{x}$ & \\
\hline 3. Smilax anceps Willd & $\mathrm{L}$ & Phgr & Sarco & GC & $\mathrm{x}$ & & \\
\hline 4. Elaeis guineensis Jacq. & A & $\mathrm{MsPh}$ & Sarco & Pan & & $\mathrm{x}$ & \\
\hline 5. Commelina diffusa Burm.f & Hvi & Chpr & Scléro & Pan & & $\mathrm{x}$ & \\
\hline 6. Cyperus angolensis Boeck. & Hvi & $\mathrm{Gr}$ & Scléro & $\mathrm{GC}$ & $\mathrm{x}$ & & \\
\hline 7. Hyparrhenia diplandra (Hack.) Stapf & Hvi & $\mathrm{Hc}$ & Scléro & Pan & $\mathrm{x}$ & & \\
\hline 8. Melinis amethystea (Franch.)Zizka. & Hvi & Hc & Scléro & Pan & $\mathrm{x}$ & & \\
\hline 9. Panicum maximum Jacq. & Hvi & Hces & Scléro & Pan & $\mathrm{x}$ & & \\
\hline 10.Pennisetum purpureum Schumach & Hvi & Hces & Pogo & Pan & & & $\mathrm{x}$ \\
\hline 11. Canna indica L. var. orientalis Baker & Hvi & $\mathrm{Gb}$ & Ballo & $\operatorname{Cos}$ & & $\mathrm{x}$ & \\
\hline 12. Aframomum alboviolaceum (Ridley.) K. Schum. & Hvi & $\mathrm{Gr}$ & Sarco & GC & $\mathrm{x}$ & & \\
\hline 13. Acacia auriculiformis A.Cunn. ex Benth & A & $\mathrm{McPh}$ & Ballo & $\operatorname{Cos}$ & $\mathrm{x}$ & $\mathrm{x}$ & $\mathrm{x}$ \\
\hline 14. Albizia lebbeck (L.) Benth & A & $\mathrm{McPh}$ & Baro & Pan & & $\mathrm{x}$ & \\
\hline 15. Calopogonium mucunoides Desv. & Han & Chgr & Ballo & Pan & & $\mathrm{x}$ & \\
\hline 16. Indigofera hirsuta L. & Han & Thd & Ballo & Pan & $\mathrm{x}$ & & \\
\hline 17. Millettia versicolor Welw. Ex Baker & A & $\mathrm{MsPh}$ & Ballo & Pan & $\mathrm{x}$ & & \\
\hline 18. Mucuna pruriens (L.) DC & Han & Thgr & Ballo & Pan & & $\mathrm{x}$ & \\
\hline 19. Psophocarpus scandens (Endl.) Verdc & Hvi & Chgr & Baro & Pan & & $\mathrm{x}$ & \\
\hline 20. Senna alata (L.)Roxb & arb & $\mathrm{NPh}$ & Ballo & Pan & & $\mathrm{x}$ & \\
\hline 21. Trema orientalis (L.) Blume & A & $\mathrm{McPh}$ & Sarco & At & $\mathrm{x}$ & & \\
\hline 22. Laportea aestuans (L.) Chew & Han & Thd & Desmo & Pal & & $\mathrm{x}$ & \\
\hline 23. Cogniauxia podolaena Bailly. & $\mathrm{L}$ & Thgr & Sarco & CGC & & $\mathrm{x}$ & \\
\hline 24. Cucumis sativus Melo. & Han & Thgr & Sarco & Pan & & $\mathrm{x}$ & \\
\hline
\end{tabular}




\begin{tabular}{|c|c|c|c|c|c|c|c|}
\hline 25. Cucurbita maxima Lam & Han & Thgr & Sarco & Pan & & $\mathrm{x}$ & \\
\hline 26. Luffa cylindrica (L.) M.J. Roem & Han & Thgr & Sarco & Pan & & $\mathrm{x}$ & $\mathrm{x}$ \\
\hline 27. Momordica charantia L. & Han & Thgr & Sarco & Pan & & $\mathrm{x}$ & \\
\hline 28. Manotes expansa Sol. Ex planch. & $\mathrm{L}$ & Phgr & Sarco & CGC & $\mathrm{x}$ & & \\
\hline 29. Anisophyllea quangens Engl. & Hvi & $\mathrm{McPh}$ & Sarco & Pan & $\mathrm{x}$ & & \\
\hline 30. Oncoba welwitschii (Coliv.) Gilg & A & $\mathrm{McPh}$ & Sarco & CGC & $\mathrm{x}$ & & \\
\hline 31. Alchornea cordifolia (Schumach\& Thom) Miille.Arg. & arb & $\mathrm{McPh}$ & Sarco & At & $\mathrm{x}$ & & \\
\hline 32. Chaetocarpus africanus Pax & arb & $\mathrm{McPh}$ & Scléro & At & $\mathrm{x}$ & & \\
\hline 33. Ricinus communis $\mathrm{L}$. & arb & $\mathrm{McPh}$ & Ballo & Pan & $\mathrm{x}$ & $\mathrm{x}$ & \\
\hline 34. Sapium cornutum Pax & arb & $\mathrm{McPh}$ & Ballo & GC & $\mathrm{x}$ & & \\
\hline 35. Hymenocardia acida Tul. & arb & $\mathrm{MsPh}$ & Sarco & At & $\mathrm{x}$ & & \\
\hline 36. Combretum racemosum P. Beauv. & $\mathrm{L}$ & Phgr & Ptero & Gc & & $\mathrm{x}$ & \\
\hline 37.Dacryodes edulis (G.Don) HJ.Lam & A & $\mathrm{MsPh}$ & Sarco & CGC & & $\mathrm{x}$ & \\
\hline 38. Sida acuta Burm & Han & Chd & Desmo & Pan & & $\mathrm{x}$ & \\
\hline 39. Carica papaya $\mathrm{L}$. & arb & $\mathrm{McPh}$ & Sarco & Pan & & $\mathrm{x}$ & \\
\hline 40. Cyathula prostrata (L.) Blume. & Han & Thpr & Desmo & Pan & & $\mathrm{x}$ & \\
\hline 41. Landolfia lanceolata (K.Schum.) Péchon. & $\mathrm{L}$ & Phgr & Sarco & GC & $\mathrm{x}$ & & \\
\hline 42. Rauvolfia mannii Stapf & arb & $\mathrm{NnPh}$ & Sarco & GC & $\mathrm{x}$ & & \\
\hline 43. Strychnos cocculoides Baker. & arb & $\mathrm{McPh}$ & Ballo & At & $\mathrm{x}$ & & \\
\hline 44.Anthocleista schweinfurthii Gilg & A & $\mathrm{McPh}$ & Sarco & CGC & $\mathrm{x}$ & & \\
\hline 45. Ipomoea batatas Poir & Hvi & Gt & Sarco & Pan & & $\mathrm{x}$ & \\
\hline 46. Ipomoea involucrata P. Beauv. & Hvi & Gt & Sarco & At & & $\mathrm{x}$ & \\
\hline 47. Capsicum annum L. Mill. & Han & Thd & Sarco & Pan & & $\mathrm{x}$ & \\
\hline 48.Capsicum frutenscens $\mathrm{L}$. & Han & $\mathrm{Nph}$ & Sarco & Aa & & $\mathrm{x}$ & \\
\hline 49. Lycopersicum esculentum Mill & Han & Thces & Sarco & Pan & & $\mathrm{x}$ & \\
\hline 50. Solanum melongena $\mathrm{L}$. & Han & Thd & Sarco & Pan & & $\mathrm{x}$ & \\
\hline 51. Solanum nigrum L & Han & Thd & Sarco & $\operatorname{Cos}$ & & $\mathrm{x}$ & \\
\hline 52. Newboudia laevis (P.Beauv) Seem. ex Bureau & arb & $\mathrm{McPh}$ & Pogo & At & $\mathrm{x}$ & & \\
\hline 53. Vitex madiensis Oliv & arb & $\mathrm{MsPh}$ & Sarco & At & $\mathrm{x}$ & & \\
\hline 54. Bidens pilosa $\mathrm{L}$. & Han & Thd & Desmo & Pan & & $\mathrm{x}$ & \\
\hline 55. Chromolaena odorata (L.) R.King \& H.Robinson & arb & Chd & Pogo & At & $\mathrm{x}$ & $\mathrm{x}$ & $\mathrm{x}$ \\
\hline 56.Conyza sumatrensis (Retz) E.Walker & Han & Thd & Pogo & Pan & $\mathrm{x}$ & & \\
\hline 57.Synedrella nodiflora Gaertn & Han & Thd & Scléro & Pan & & $\mathrm{x}$ & \\
\hline 58. Dracaena mannii Baker & A & $\mathrm{McPh}$ & Sarco & At & $\mathrm{x}$ & & \\
\hline 59. Adansonia digitata $\mathrm{L}$ & A & $\mathrm{MgPh}$ & Pogo & Pan & & $\mathrm{x}$ & \\
\hline \multicolumn{5}{|l|}{ Total } & 28 & 33 & 4 \\
\hline
\end{tabular}




\subsection{Ecological analysis}

Figure 2 illustrates the ecological characteristics taken into account

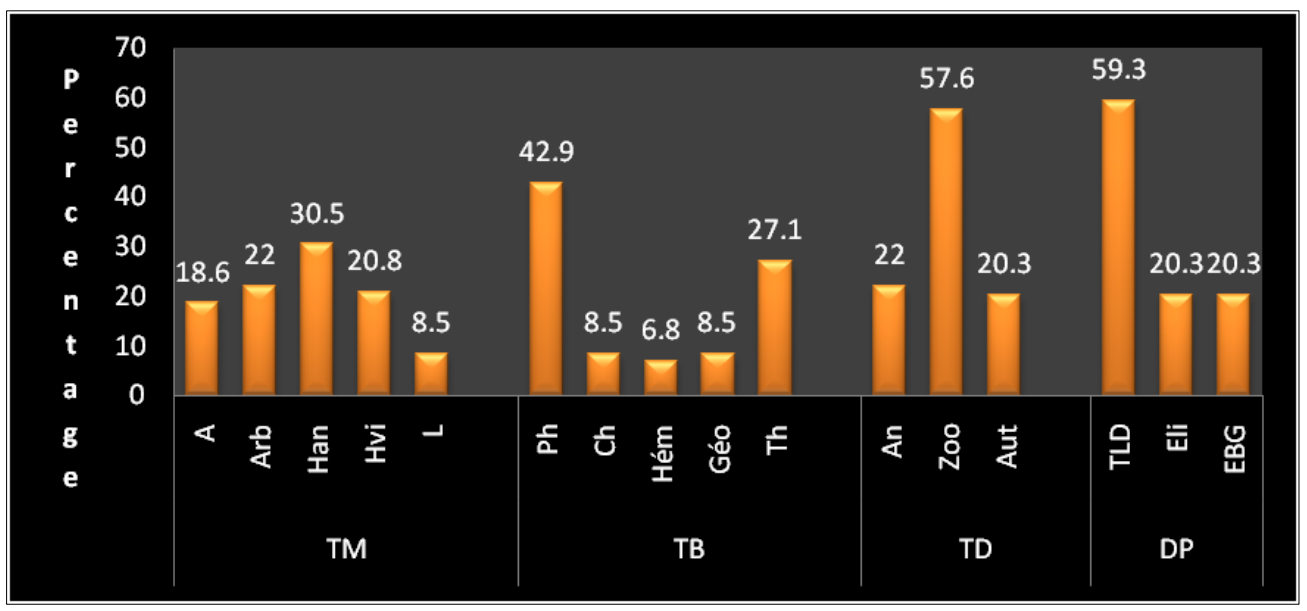

Figure 2 Morphological, biological types, types of diaspores and Phytogeographical distribution of the inventoried species

\subsubsection{Morphological types}

Annual grass (Han) is the best represented morphological type with $30.5 \%$ followed by shrub (arb) with $22 \%$, perennial grass (Hvi) with $20.8 \%$, tree (A) with $18.6 \%$ and finally liana with $8.5 \%$.

\subsubsection{Biological types}

The analysis of the biological types reveals that the flora of the environment studied is ecologically diversified.

Phanerophytes are largely in the majority with 29 species or 48.1\%. Microphanerophytes (McPh) contain 14 species (i.e. 14.7\%). They are followed by mesophanerophytes (MsPh) with 7 species (i.e. 11.8\%). Climbing phanerophytes (Phgr) represent 4 species (i.e. 6.8\%). Nanophanerophytes (NPh) are involved with 3 species (i.e. 5.1\%). Finally, megaphanerophytes $(\mathrm{MgPh})$ are rare with 1 species (i.e. 1.7\%).

Therophytes (Th) occupy the second position with 16 species (i.e. 27.1\%). Erect therophytes (Thd) predominate with 8 species (i.e. 13.6\%) They are followed by climbing therophytes with 6 species (i.e. 10.1\%). Finally, the cespitose therophytes and the prostrate therophytes are each represented by 1 species (i.e. 1.7\%).

The chamaephytes $(\mathrm{Ch})$ and the geophytes $(\mathrm{Gh})$ each intervene with 5 species (i.e. 8.5\%). Among the chamaephytes, the erect ones and the climbers are each represented by 2 species (i.e. 3.4\%) and the prostrate by 1 species (i.e. $1.7 \%$ ). Among the geophytes, tuberous (Gt) and rhizomatous (Gr) each have 2 species (i.e. 3.4\%) and bulbous geophytes (Gb) with only 1 species (i.e. 1.7\%). Finally, hemi-cryptophytes include 4 species (i.e. $6.8 \%$ ).

\subsubsection{Diaspore types}

Zoochorous plants occupy the first place with 34 species (i.e. 57.6\%) where there is a predominance of sarcochorous (Sarco) represented by 30 species (i.e. 50.8\%), followed by desmochorous (Desmo) with 4 species (i.e. 6.8\%).

Anemochorous plants have 13 species (i.e. 22.1\%) where sclerochorous (Sclero) are represented by 7 species (i.e. 11.9\%), pogonochorous (Pogo) with 5 species (i.e. 8.5\%) and pterochorous (Ptero) with 1 species (i.e. 1.7\%).

Autochorous plants include 12 species (i.e. 20.3\%) where ballochorous (Ballo) predominate with 10 species (i.e. 16.9\%) and barochorous (Baro) with only 2 species (i.e. 3.4\%).

\subsubsection{Phytogeographic Distribution}

Very wide distribution species predominate with 35 species (i.e. 59.3\%) including 
- $\quad$ Pantropical species (Pan) (50.8\%);

- Cosmopolitan species (Cosmo) (5.1\%);

- $\quad$ Paleotropical (Pal) species (1.7\%) and

- Afro-American (Aa) species (1.7\%).

The bonding species are represented by 12 species (i.e. 20.3\%). They all belong to the category of Afro-tropical species.

The species of the Guinean base element include 12 species (i.e. 20.3\%). They are divided into

- Guinean-Congolese species (GC) (11.9\%) and

- $\quad$ Centro-Guineo-Congolese species (CGC) (8.5\%).

3.2.5. Number of plant species per site

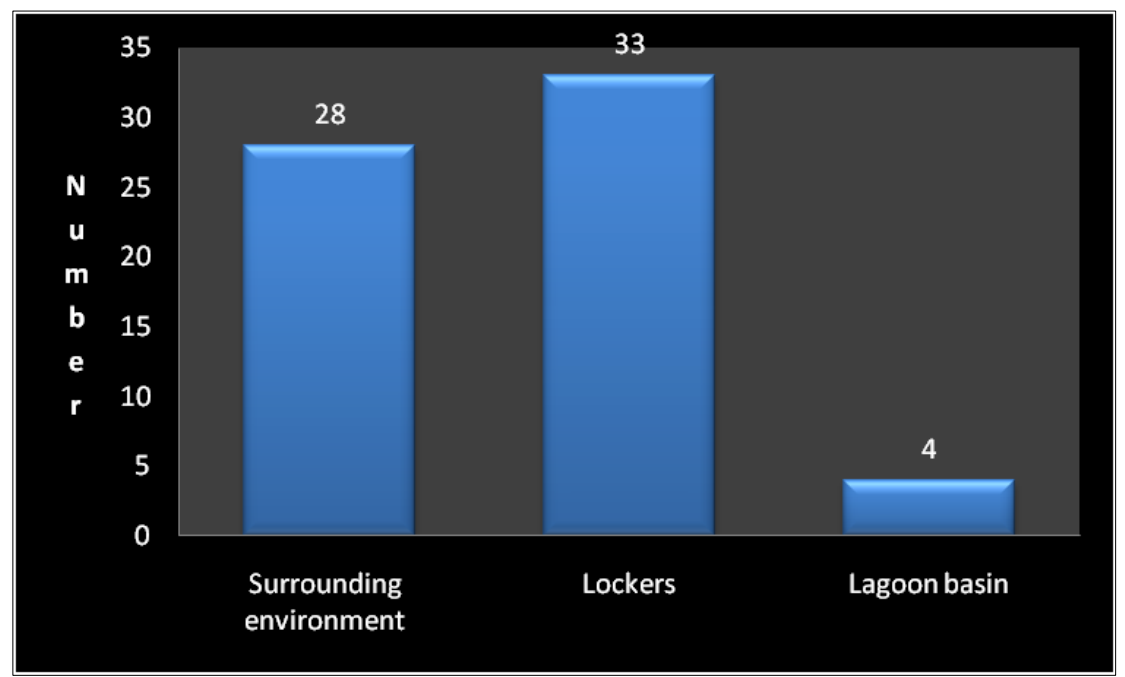

Figure 3 Number of species per site

The lockers are floristically richer (33 species) than the other sites. The surrounding environment which served as a control comes in second place with 28 species. The lagooning basin, specific pauci, has only 4 species.

Acacia auriculiformis and Chromolaena odorata grow at all three sites; Luffa cylindrica is recorded both in lockers and lagoons while Ricinus communis is found both in lockers and in the surrounding environment. The other species grow either on the lockers, or on the lagoon basins, or on the surrounding environment.

Table 2 Comparative analysis of the similarity index

\begin{tabular}{|l|c|c|c|}
\hline & Lockers & Lagoon basin & Surrounding environment \\
\hline Surrounding environment & 0.1 & 0.125 & 1 \\
\hline Lagoon basin & 0.162 & 1 & \\
\hline Lockers & 1 & & \\
\hline
\end{tabular}

This table summarizes the indices of similarities of different sites explored. His analysis shows that the indices resulting from the comparison of the sites two by two do not exceed the figure 3. It follows that the Technical Waste Landfill Center has largely contributed to modifying the environment of MPASA by introducing new species.

\subsection{Soil study}

Figure 4 shows the variation in the average $\mathrm{pH}$ of the sites 


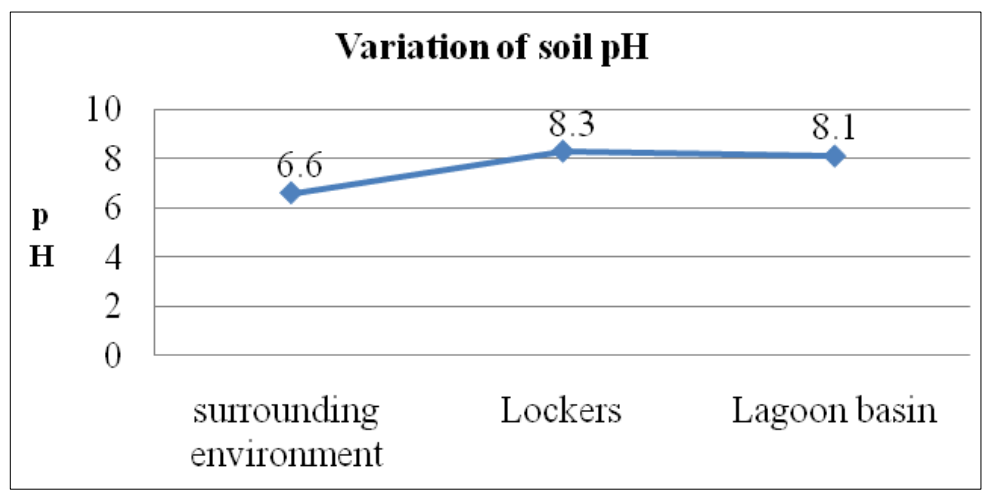

Figure 4 Variation of soil $\mathrm{pH}$ according to sites

The average $\mathrm{pH}$ of the surrounding medium is equivalent to 6.6. It follows that the soil is slightly acidic. The average $\mathrm{pH}$ values of the soil sampled at the Compartments and the lagoon basin are respectively 8.3 and 8.1. These last two values prove that the soils there are basic.

\section{Discussion}

In a study of the flora of the botanical garden of Kinshasa, Cakupewa [21] listed 341 species distributed in 254 genera, 883 families and 41 orders. Spermatophytes predominate the floristic set. The Magnoliopsida intervene for $67.44 \%$ of the floristic set. On the other hand, Muhindo[22] listed 2473 species in the Kisantu botanical garden. The florule is divided into 1113 genera, 66 orders and 166 families. The Spermatophytes are the best represented there and dominated by the Magnoliopsida with 1360 species (i.e. 54.99\%) of the floristic set. The Liliopsida are involved with 381 species (39.67\%) of the florule. In the Masina marshes, Kifuki and Lukoki [23] report the presence of 264 species including 10 Pteridophyta and 254 Magnoliophyta.

Compared to the results of the aforementioned authors, the Technical Waste Landfill Center of Kinshasa, which has 59 species, is very poor. However, the study reveals that the lockers are floristically richer (33 species) than the other sites. The surrounding environment which served as a control comes in second place with 28 species. The lagooning basin, specific pauci, has only 4 species.

The implantation of the Technical Waste Landfill Center in Mpasa has modified the floristic composition of the local vegetation. The diaspores included in the domestic waste have grown in the lockers. Indeed, the species found on the lockers are frequent in the city.

A disturbance is defined as a change in a factor in the environment of a biological system that interferes with its initial functioning $[24,25]$. It is defined by its nature which depends on the type of factor concerned, its intensification determined by the difference between the resulting state and the normal state of the system, by its frequency and its scale, i.e. either by its spatio-temporal characteristics, or by the level of organization of the system where it operates [26]

The results obtained corroborate those of Debril et al. [27]. They observed that exotic plants from South America invaded and colonized the different ecosystems after being used as compost in the Parc de Brière in France. For his part, Segbeaya [28] assessed the impact of solid waste in the Kara River in Togo.

TWLC had effects on soil pH. At $\mathrm{T}_{0}$, the soil is slightly acidic. Under the influence of TWLC, it is slightly basic at $\mathrm{T}_{1}$ and $\mathrm{T}_{2}$. The values of the soil samples at the level of the lagoon basins and the lockers confirm the facts. Variations in chemical parameters $(\mathrm{pH}$, electrical conductivity, salinity, organic matter, total organic carbon, total nitrogen, $\mathrm{C} / \mathrm{N}$ ratio, potassium and phosphorus contents) were also observed by M'Sadak et al. [29] in their study on the evaluation of the chemical behavior of forestry composts.

\section{Conclusion}

Our study aimed to assess the environmental impact of the Technical Waste Landfill Center on the flora of MPASA. For this purpose, three sites were selected according to their affinities with the TWLC. 
The floristic inventory amounts to:

- 33 on the lockers

- 28 in the surrounding environment

- 4 on the lagoon basins

The lockers are therefore richer in plant species than the surrounding environment and the lagoon basins.

Analyzes of the $\mathrm{pH}$ of different soil samples indicate that the $\mathrm{pH}$ of the surrounding environment is slightly acidic (6.55). At the level of the lagoon basins and lockers, it is slightly alkaline with the respective average values of 8.9 and 8.26 . The comparison of the three sites reveals that the TWLC has had an impact on the environment of Mpasa. In fact, the medium that served as a control has a slightly acidic soil, whereas the lagooning basin and the locker derived from the TWLC have a slightly basic $\mathrm{pH}$.

The dissimilarity between the three sites is confirmed by the SORRENSEN indices. Compared two by two, the sites show similarity indices below $16.2 \%$. It follows that the Kinshasa Technical Waste Landfill Center has brought environmental changes with the consequent introduction of new species in the lockers.

\section{Compliance with ethical standards}

\section{Disclosure of conflict of interest}

There is no conflict of interest between the authors of this manuscript.

\section{References}

[1] JM. Balet, Waste Management 5th edition Dunod Paris. 2016.

[2] S Cointreau-Levine. Private Sector Participation in Municipal Solid Waste Services in Developing Countries. Volume 1. The Formal Sector, World Bank. 1994; 59.

[3] P Schübeler, Conceptual Framework for Municipal Solid Waste Management in Low-Income Countries, UNDP, World Bank, SDC. 1996; 59.

[4] L Debout. Urban governments under authoritarian regimes. The case of household waste management in Egypt. Architecture, spatial planning. Lumière University - Lyon II, 2012. French. tel-00801650v2

[5] E Dorier-Apprill. Water and waste management in cities in developing countries", in E. Dorier-Appril (dir.), City and environment, Paris, Sedes. 2006; 385-413.

[6] E Ngnikam and E Tanawa. The cities of Africa facing their waste University of Technology of BelfortMontbéliard2006 Accessed on December 6. 2021.

[7] S Aliouche, Kehila Y, Benkahoul L. Modalities for the selection of technical landfill sites in Algeria and their management by regional planning and urban planning instruments. Science and technology waste. 2017; 75: 110.

[8] J Mery, R Mtibaa and A.Torre. Proximity dynamics and waste management: application to landfill. 6th days of proximity, time for debates, Oct 2009, Poitiers, France. 8. hal-00473256.

[9] J Matondo. Internship report carried out at RSKIN. Unpublished. 2019; 20.

[10] N Ilunga. Internship report carried out at RASKIN. Unpublished. 2020; 23.

[11] R Schnel. Introduction to the phytogeography of tropical countries: general problems, environments, plant groups, Gauthier-Villars, Paris. 1971; Flight. II: 951.

[12] C Evrard. Ecological research on the forest population of the hydromorphic soils of the Congolese central basin. INEAC. Scientific series. Brussels. 1968; 110:295.

[13] P Gerard. Study of the dense forest with Gilbertiodendron dewevrei in the Uélé region, publ. INEAC, Scientific Series. Brussels. 1960; 87:159. 
[14] MA Mandango. Flora and vegetation of the Zaire River Islands in the Tshopo sub-region (Haut-Zaire), Doctoral Thesis, UNIKIS, Fac. Science. 1982; 425.

[15] J Lejoly, B Sonke, and K Van Essche, Using the transect method for biodiversity in the Dja Faunal Reserve (Cameroon): The biodiversity of African plants, Kluwer Academic Publishers printed in the Netherlands. 1996; 150-154.

[16] MK Habiyaremye. Phytocoenological study of the eastern ridge of Lake Kivu (Rwanda). Royal Museum of Central Africa. Tervuren, Belgium, Annales Sciences Economiques. 1997; 24:276.

[17] H Belesi. Floristic, phytogeographical and phytosociological study of the vegetation of Bas - Kasaï in the Democratic Republic of Congo, Thesis Doct., Fac.Sc. UNIKIN. 2009; 565. + annexes.

[18] M Habari, Floristic, phytogeographical and phytosociological study of the vegetation of Kinshasa and the middle basins of the N'djili and N'sele rivers in the Democratic Republic of Congo, Thesis Doct., UNIKIN. 2009; 273. + annexes.

[19] PF Stevens, Angiosperm Phylogeny Website.Version 14, July 2017 Accessed November 19, 2020 at

[20] J Lejoly and MA Mandango, Riparian Shrub Association with Alchornea cordifolia in Upper Zaire. Roy Bot In studies on Aquatic vascular Plants. 1982; (e-265).

[21] M Cakupewa, Flora of the Botanical Garden of Kinshasa T.F.C Department of Biology, IPN Kinshasa Unpublished. $1993 ; 43$.

[22] K Muhindo, Living collection of the Kisantu Botanical Garden, TFE, Dep. Biology, IPN, Kinshasa, Unpublished. 1990; 105.

[23] BA Kikufi, and FL Lukoki, Floristic and ecological study of the marshes of Masina. Congolese review of nuclear sciences. 2008; 23(1): 1-19.

[24] EJ Rykiel. Towards a definition of ecological disturbance. Australian Journal of Ecology. 1985; 10: 361-365.

[25] J Van Andel and JP Van der Bergh, Disturbance of grassland. Outline of the theme. In Van Andel J. et al. (Eds) Disturbance in grasslands. DrW. Junk Publishers, Dordrecht. 1987; 3-13.

[26] G Balent, M Duru and D Magda, Management practices and vegetation dynamics of permanent grasslands. Studies and Research on Agrarian Systems and Development. 1993; 284-301.

[27] J Debril, R Matrat and J Haury. Management of Jussie waste by composting.DIREN of Pays de la Loire, UMR INRA Agrocampus EQHC, Rennes. 2005; 37.

[28] KN Segbeaya. Evaluation of the impact of household waste from the city of Kara (Togo) on the quality of the Kara River. 2012. Doctoral thesis. Limoges.

[29] Y M'sadak MA Elouaer, RE Kamel. Evaluation of the chemical behavior of forestry composts, sieves and mixtures for the design of culture substrates Revue Nature et Technologie. 2013; 5(1): 54-60. 